\title{
Influence of levamisole and Freund's adjuvant on mouse immunisation with antigens of adults of the liver fluke Fasciola hepatica Linnaeus, 1758
}

\author{
María de los Ángeles Gutiérrez-Sánchez ${ }^{1}$, Julieta Luna-Herrera ${ }^{2}$, Lauro Trejo-Castro ${ }^{3}$, Natividad Montenegro- \\ Cristino $^{3}$, Alfredo Almanza-González ${ }^{1}$, Alejandro Escobar-Gutiérrez ${ }^{1}$ and Jorge Luis de la Rosa-Arana ${ }^{1}$ \\ ${ }^{1}$ Instituto de Diagnóstico y Referencia Epidemiológicos, Secretaría de Salud, México D. F., Mexico; \\ ${ }^{2}$ Escuela Nacional de Ciencias Biológicas, Instituto Politécnico Nacional, México D. F., Mexico; \\ ${ }^{3}$ Centro Nacional de Servicios de Constatación en Salud Animal, Secretaría de Agricultura, Ganadería, Desarrollo Rural, Pesca y \\ Alimentación, Morelos, Mexico
}

\begin{abstract}
We have studied the influence of both levamisole (AL) and Freund's adjuvant (AF) on the immunisation of mice with the secretory antigens of adults of the liver fluke Fasciola hepatica Linnaeus, 1758. Total IgG antibodies were detected in all groups where the $F$. hepatica antigen was administered, been levels of IgG1 increased respect to IgG2a antibodies. During immunisation, IL-4 and IFN- $\gamma$ were only detected in AL and AF groups, but after infection, IL-4 boosted in all groups. IFN- $\gamma$ increased two fold in AF and AL groups compared to the saline solution (AS) group. Worm recovering was of $32-35 \%$ in groups administered without antigen whereas in $\mathrm{AS}, \mathrm{AL}$ and $\mathrm{AF}$ groups recovering was of $25 \%, 12 \%$ and $8 \%$, respectively. Macroscopical lesions in the liver were scarce in $\mathrm{AL}$ and AF groups. Our data suggest that immunisation of mice with antigens of $F$. hepatica enhances the immune response avoiding both liver damage and worm establishment after challenge infection. The murine model of fasciolosis has appeared to be useful to elucidate the mechanism by which the parasite modulates immune responses toward a Th2 type but also the development of Th1 type-inducing vaccines.
\end{abstract}

Keywords: helminth, fasciolosis, immunomodulation, vaccine, immunity

Helminth infections are associated with development of dominant Th2-mediated immune responses, which may be host-protective but can also be the cause of immunopathology. Studies using Nippostrongylus brasiliensis Travassos, 1914 and Trichuris muris (Schrank, 1788) as laboratory models of infection in mice, have concluded that Th2-mediated immune responses are primarily responsible for host protection and expulsion of these intestinal nematodes. However, administration of rIL-12 during primary infections outcomes IgE, eosinophily and mastocytosis inhibition, enhancing worm survival (Mountford and Pearlman 1998).

Eosinophily is a hallmark of helminth infections and in some host-parasite relationships, eosinophils have been observed to kill worms. In vitro studies have shown that eosinophils, in association with specific antibodies, can kill the nematodes Trichinella spiralis Owen, 1835, Haemonchus contortus Rudolphi, 1803, Onchocerca volvulus Leuckart, 1894 and Strongyloides stercoralis Bavay, 1876 (see Venturiello et al. 1995, Bell 1996, Klion and Nutman 2004, O’Connell et al. 2011, Cadman et al. 2014).
However, the tissue helminthic infections are successful in the body host even in presence of IgE, eosinophils and mast cells. Recent studies have shown that muscle larvae of $T$. spiralis do not survive if Th2 cells are diminished and a concomitant activity of inducible nitric oxide synthase is increased (Fabre et al. 2009, Gebreselassie et al. 2012). Indeed, the immunisation of rats with antigens of $T$. spiralis in Freund's adjuvant showed a significant increase in the production of IFN- $\gamma$, resulting in $86 \%$ protection against the experimental infection (de la Rosa-Arana et al. 2012).

The relationship Th1/Th2 is also exemplified during the infection with the liver fluke Fasciola hepatica Linnaeus, 1758. Adult worms live inside the bile ducts of sheep, cattle and accidentally in man but young (or immature) parasites must migrate through the tissues of the host to settle in the liver. During migration, parasites produce molecules to evade the host immune response (McManus and Dalton 2006, Piedrafita et al. 2010, Smooker et al. 2010).

Thus, the development of vaccines to control fasciolosis is seen as a desirable alternative to antiparasitic drugs. The identification of molecules that play critical functions at

Address for correspondence: J.L. de la Rosa-Arana, Instituto de Diagnóstico y Referencia Epidemiológicos, Secretaría de Salud, Francisco de Paula Miranda 177, Lomas de Plateros, México D. F., 01480, Mexico. Phone: +52-55-50621600 ext. 59349; Fax: +52-55-50621600 ext. 59349; E-mail: jorgeluis.delarosa@yahoo.com 
the host-parasite interface represents prime targets to direct vaccine-induced immune responses. Adults worms of $F$. hepatica adult worm secrete a variety of molecules that direct the immune response towards a favourable non-protective Th2-mediate/regulatory environment, like the excretory secretory antigens of $F$. hepatica which have been widely studied by Dalton et al. (2013).

Adjuvants can influence the T-helper cell polarisation creating bias towards Th1 or Th2 immune responses (Guy 2007), but some adjuvant substances have toxic or undesirable side effects. Hence, seeking for non-toxic adjuvants is an important task. Levamisole hydrocholoride, an imidazolthiazole derivative, is the $\mathrm{L}$ isomer of DL-tetramisole. Injectable levamisole has a high level of anthelmintic activity against most gasterointestinal and respiratory tract nematodes of agricultural animals. Recently, levamisole has been reported to effect both humoral and cellular immune responses in humans and animals and it has been used as an enhancer of Th1 immune response (Sajid et al. 2006, Yin et al. 2006) as well as adjuvant with antigens of the trematode Schistosoma japonicum Katsurada, 1904 (see Wang et al. 2008). Levamisole also has been used during the treatment of chronic infections (Cuesta et al. 2002) and during chemotherapy (Hajnzić et al. 1999). Since data about the effectiveness of different adjuvant substances in mice immunisation with $F$. hepatica antigens is scarce, the aim of this work was to compare the effects of levamisole and Freund's adjuvant on mice immunised with excretory and secretory antigens of adult worms of $F$. hepatica.

\section{MATERIALS AND METHODS}

\section{Adult worms of Fasciola hepatica}

Livers with adults of $F$. hepatica were obtained from goats experimentally infected at Centro Nacional de Servicios de Constatación en Salud Animal, Ministry of Agriculture, Mexico. Livers were longitudinally sectioned to expose the bile ducts, from where the adult worms of $F$. hepatica were carefully extracted and placed at $37^{\circ} \mathrm{C}$ in a Petri dish with sterile $0.01 \mathrm{M}$ phosphatebuffered $0.15 \mathrm{M}$ saline and $\mathrm{pH} 7.2$ (PBS); subsequently, adult worms were washed five times with PBS and two more times with sterile RPMI 1640 medium.

\section{Preparation of antigens from adults of Fasciola hepatica}

Excretory and secretory antigens of adults of $F$. hepatica were prepared by in vitro culture of 50 parasites at $37^{\circ} \mathrm{C}$ for $24 \mathrm{~h}$ in a humid atmosphere of $95 \%$ air and $5 \% \mathrm{CO}_{2}$, using $50 \mathrm{ml}$ of RPMI 1640 medium containing 100 IU penicillin G and $100 \mathrm{mg}$ streptomycin/ml (Gibco BRL, Grand Island, NY, USA). Supernatant was collected, pooled and clarified at $750 \times \mathrm{g}$ for $15 \mathrm{~min}$. After protein quantification with the Bradford dye reagent (BioRad, Hercules, CA, USA), protein inhibitor cocktail was added for each $0.85 \mathrm{ml}$ of antigen, using $0.05 \mathrm{ml}$ of TPCK $(1 \mathrm{mg} / \mathrm{ml}$ in methanol), $0.05 \mathrm{ml}$ of TLCK $(1 \mathrm{mg} / \mathrm{ml}$ in water $), 0.040 \mathrm{ml}$ of PHMB $(0.04 \% 2 \mathrm{~N} \mathrm{NaOH}), 0.006 \mathrm{ml}$ of PMSF $(0.06 \%$ in isopropanol) and $0.004 \mathrm{ml}$ of EDTA $(1 \mathrm{M})$. Antigen was stored at $-20^{\circ} \mathrm{C}$ and then at $-70^{\circ} \mathrm{C}$ (Tinoco-Velázquez et al. 2002). Before starting the immunisation schedule, the antigen was exhaustively dialysed against PBS.

\section{Lymnaea in vitro culture}

Petri dishes were coated with sterile mud clay and $2 \mathrm{ml}$ of a $30 \%$ suspension of blue-green algae of the genus Oscillatoria Vaucher et Gomont; the microalgae were thoroughly washed with tap water before used in the culture. Light was provided to the culture in cycles of 12 hours by mean of helium lamps and fresh water was added every third day until the end of the experiment. Snails of the genus Lymnaea Lamarck, 1799 were collected from a freshwater ecosystem in State of Morelos, Mexico, where bovine fasciolosis was previously reported (Ibarra et al. 1998). Snails were placed in three days old cultures. When the snail oviposited, the ovigerous masses were removed to be incubated in fresh cultures of cyanophyta during 15 days at room temperature. The newborn snails were removed with a spoon and placed in fresh microalga cultures, providing daily maintenance, removing faeces, dead snails and changing culture when necessary. Snails 12 days old were used to obtain metacercariae or, were used to preserve the population of snails.

\section{Metacercariae of Fasciola hepatica}

Faeces of experimentally infected bovines with $F$. hepatica were collected to concentrate its eggs by sedimentation, after a carefully washing with tap water, the eggs were incubated at $29^{\circ} \mathrm{C}$ during 10 days in fresh water to induce the hatching of miracidia. Experimental infection of snails Lymnaea cubensis Pfeiffer (synonyms Galba cubensis Pfeiffer) was carried out in wells of microtitre plates (Corning-Life Sciences, Corning, NY, USA). Each well was supplied with four miracidia, one snail and $0.3 \mathrm{ml}$ of distillated water. Plates were incubated at room temperature during $3 \mathrm{~h}$, providing fresh water if necessary. To obtain metacercariae, L. cubensis snails were cultured on a substrate of cyanophyta and were checked daily with a stereoscopic microscope to identify the presence of rediae inside of them. Non-infected snails were removed from culture. At day 40 postinfection, snails were placed in a $100 \mathrm{ml}$ glass beaker internally lined with wax paper, which was drawn with squares of $1 \mathrm{~cm}^{2}$ and provided with fresh water and two ice cubes. The glass beaker was incubated at room temperature under the light of a helium lamp during $48 \mathrm{~h}$. The cercariae were attached to the wax paper and then developed into metacercarie; then they were counted and then keep at $4{ }^{\circ} \mathrm{C}$.

\section{Experimental model}

Female BALB/c mice 4 weeks old and weighing $20 \mathrm{~g}( \pm 1 \mathrm{~g})$ were used during all experiments. All animals were housed in controlled light and temperature conditions and handled according to the Research and Animal Care Committee of the Institute for Epidemiological Diagnosis and Reference approved protocol number INV-2011-06, following the Mexican Regulation NOM-062-ZOO-1999 for the care and use of laboratory animals (Norma Oficial Mexicana). To establish the experimental F. hepatica model, each animal was infected orally with 13 metacercariae which were contained in $0.02 \mathrm{ml}$ of distillate water. Mice were infected with 13 metacercariae to obtain moderate infection since it has been previously reported that infections, whereas 5 metacercariae correspond to a low infection while, infections with 15 metacercariae correspond a high infection (O'Neill et al. 2000). After five weeks postinfection, flukes were recovered from the liver by dissection. Determination of the number of parasites was performed microscopically. The experimental design was 
performed in three independent occasions with similar results. Individual analysis of samples were performed in triplicate.

\section{Immunisation of animals}

Six groups of mice were formed $(n=5)$; three groups received six subcutaneous doses of antigen $(10 \mu \mathrm{g})$ in combination with one of two adjuvant substances or in saline solution. The compound administration was performed in the anterolateral region of the thigh. Doses of $0.1 \mathrm{ml}$ were administered once per week during 4 weeks, followed by 1 week of repose and then, the final doses at the sixth and seventh weeks. A total of six injections were given to ensure the determination of IgG isotypes. The remaining three groups were administered with one dosis of the adjuvant substances without antigen. In the first group (AS), the antigen was mixed with $10 \mathrm{mM}$ phosphate-buffered $150 \mathrm{mM}$ saline and $\mathrm{pH}$ 7.2. In group $2(\mathrm{AL})$, the antigen was mixed in $0.1 \mathrm{ml}$ of $0.05 \%$ levamisole (Sigma-Aldrich, St. Louis, MO, USA), equivalent to $1.6 \mathrm{mg} / \mathrm{kg}$. In group $3(\mathrm{AF})$, the antigen was diluted $1: 2$ in complete Freund's adjuvant to be administered once in the beginning of immunisation and then, the antigen was diluted $1: 2$ in the incomplete adjuvant to be administered once in the second doses of immunisation; the rest of doses were administered intramuscularly in a saline solution. Group 4 was administered with levamisole (LV), group 5 with Freund's adjuvant (FA) and the group 6 with a saline solution (SS). At the end of the immunisation schedule, all animals were infected perorally with 13 metacercariae. The parasitic burden was calculated for every group and the macroscopical lesion of the liver was verified at day 42 postinfection in each group. Levels of IgG1, IgG2a, IL-4 and IFN- $\gamma$ were determined in serum samples pre-, postimmunisation and postinfection. Representative data of three independent observations are summarised in the results section. All tests were performed in triplicate and experiments repeated three times.

\section{Antibodies and cytokines}

Specific IgG antibodies to excretory and secretory antigens of adults of $F$. hepatica adult worm, were tested by ELISA and Western blot (WB). The optimal conditions for ELISA was performed by testing several dilutions of serum samples and horseradish peroxidase conjugate to anti-mouse IgG (Sigma-Aldrich, Inc.). Each well of flat-bottom microtiter polystyrene plates (Corning-Life Sciences, Corning, NY, USA) was coated with $250 \mathrm{ng}$ of antigen diluted in $50 \mu$ of $100 \mathrm{mM}$ carbonate-bicarbonate buffer $\mathrm{pH} 9.6$ and then blocked with $5 \%$ of slime fast milk. A total of $0.3 \mathrm{mg}$ of antigen was electrophoresed in an $18 \%$ SDS - polyacrylamide gel under reducing conditions and blotted onto a nitrocellulose membrane using a semi-dry vertical electro-transfer system (BioRad). Serum samples were diluted at $1: 1000$ for ELISA and at $1: 500$ for Western blot. The conjugate was diluted at $1: 2000$ and at $1: 1000$, respectively. The reactivity of assays was evidenced using O-phenilendiamine for ELISA $(\mathrm{A}=490 \mathrm{~nm})$ and 4-Chloro Naphtol for WB (de la Rosa-Arana et al. 2012). To detect IgG isotypes by ELISA, serum samples were used in double serial dilutions beginning at $1: 50$ and goat anti-mouse IgG1 or anti-mouse IgG2a (Thermo Fisher Scientific Inc., Rockford, IL, USA) were used at $1: 3000$. Reactivity was evidenced with an alkaline-phosphatase conjugates to anti-goat IgG (Sigma-Aldrich) diluted 1: 4000 and p-nitrophenilphosphate $(\mathrm{A}=405 \mathrm{~nm})$. Two cytokines, IL-4 and IFN- $\gamma$, were tested in serum samples by using

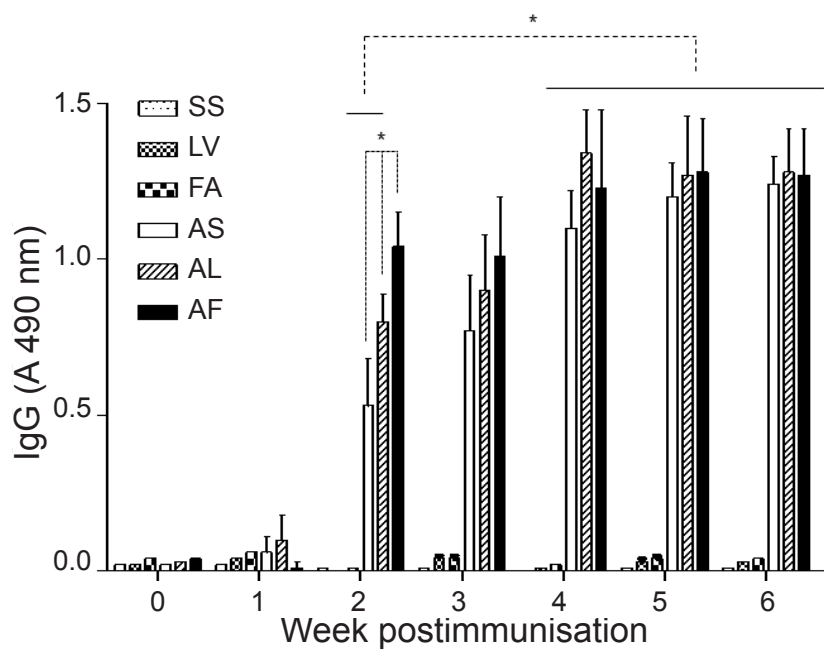

Fig. 1. Antibody kinetics in mice immunised with the excretory and secretory antigens of adults of Fasciola hepatica. Specific IgG antibodies were determined by ELISA once a week during the immunisation schedule. Three groups of mice were immunised with the antigen in a saline solution (AS), in levamisole (AL) or in Freund's adjuvant (AF). The remaining groups were administered only with the saline solution (SS), levamisole (LV) or Freund's adjuvant (FA). Statistical differences were determined by the two-way ANOVA ( $*, \mathrm{P}<0.05)$.

the Thermo Scientific Pierce Mouse IL-4 ELISA kit and Thermo Scientific Pierce Mouse IFN- $\gamma$ ELISA kit (Thermo Fisher Scientific Inc.).

\section{Macroscopic analysis of livers and parasite load}

Macroscopic analysis of liver was performed at fifth week postinfection. The necropsy involved the analysis of internal organs and particularly, the liver of each mouse was weighed, measured and reviewed to recuperate the worms. The parasite load was determine as follows: parasitic load $(\%)=[$ (recovered worm mean in the experimental group / recovered worm mean in the naive group) $\times 100]$ and the percent of parasite implantation was obtained as follow: implementation $(\%)=[($ recovered worm mean in the experimental group / 13 , which represents the number of metacercariae employed for challenge infection) $\times 100$ ]

\section{Data processing and statistical analysis}

To establish the relationship between the effect of the adjuvant substance during the time of immunisation and the kinetic of IgG production, a two-way ANOVA for fixed effects was employed. Data on recovered parasite and results of IgG isotypes and cytokines were analysed by the one-way ANOVA test (DawsonSaunders and Trapp 2001). In all cases, additional contrast tests were performed. Data in figures are presented as mean \pm standard deviation.

\section{RESULTS}

\section{Antibody kinetics}

Specific IgG antibody level was increased with the progression of the immunisation period (Fig. 1). However, variations in the response were observed between groups. At week 2 postimmunisation, IgG antibodies ap- 


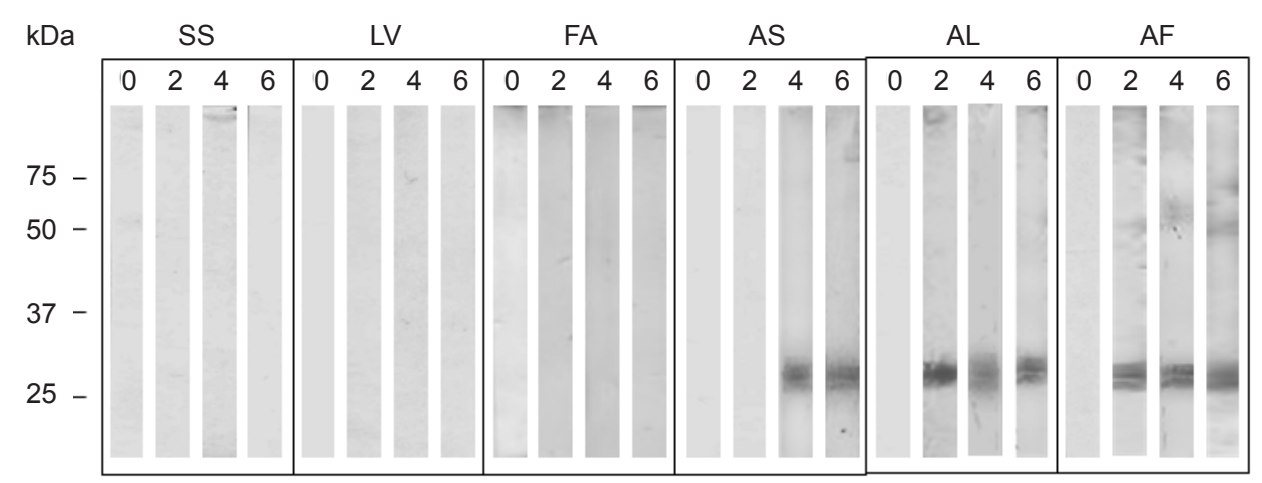

Fig. 2. Western blot analysis of serum samples of mice immunised with the excretory and secretory antigens of adults of Fasciola hepatica.Reactivity of serum samples of mice administered only with a saline solution (SS), levamisole (LV) or Freund's Adjuvant (FA) is shown. Reactivity of mice immunised with the antigen in a saline solution (AS), levamisole (AL) or Freund's adjuvant (AF) is also shown. Molecular weight markers are indicated to the left of the panel.

Table 1. Relationship between the liver and the body weight of experimental infected mice.

\begin{tabular}{lcccccc}
\hline & SS & LV & FA & AS & AL & AF \\
\hline Liver weight (g) & $1.6 \pm 0.1$ & $1.5 \pm 0.1$ & $1.4 \pm 0.1$ & $1.4 \pm 0.1$ & $1.3 \pm 0.1^{*}$ & $1.0 \pm 0.1^{*}$ \\
Body weight (g) & $22.1 \pm 1.6$ & $22.7 \pm 1.0$ & $22.5 \pm 1.3$ & $19.8 \pm 1.4^{*}$ & $24.4 \pm 2.7^{*}$ & $22.6 \pm 0.8$ \\
Relationship liver/body & $0.072 \pm 0.003$ & $0.067 \pm 0.004$ & $0.062 \pm 0.006$ & $0.074 \pm 0.010$ & $0.052 \pm .005^{*}$ & $0.044 \pm 0.004^{*}$ \\
\hline
\end{tabular}

Table shows data of animals administered with a saline solution (SS), levamisole (LV) or Freund's adjuvant (FA). The remaining groups were immunised with the excretory and secretory antigens of adult worm of Fasciola hepatica adult worm in a saline solution (AS), levamisole (AL) or Freund's adjuvant (AF). Statistical analysis was performed by the one-way ANOVA and the Turkey HD contrast test, statistical differences $(P<0.05)$ between groups are marked $(*)$.
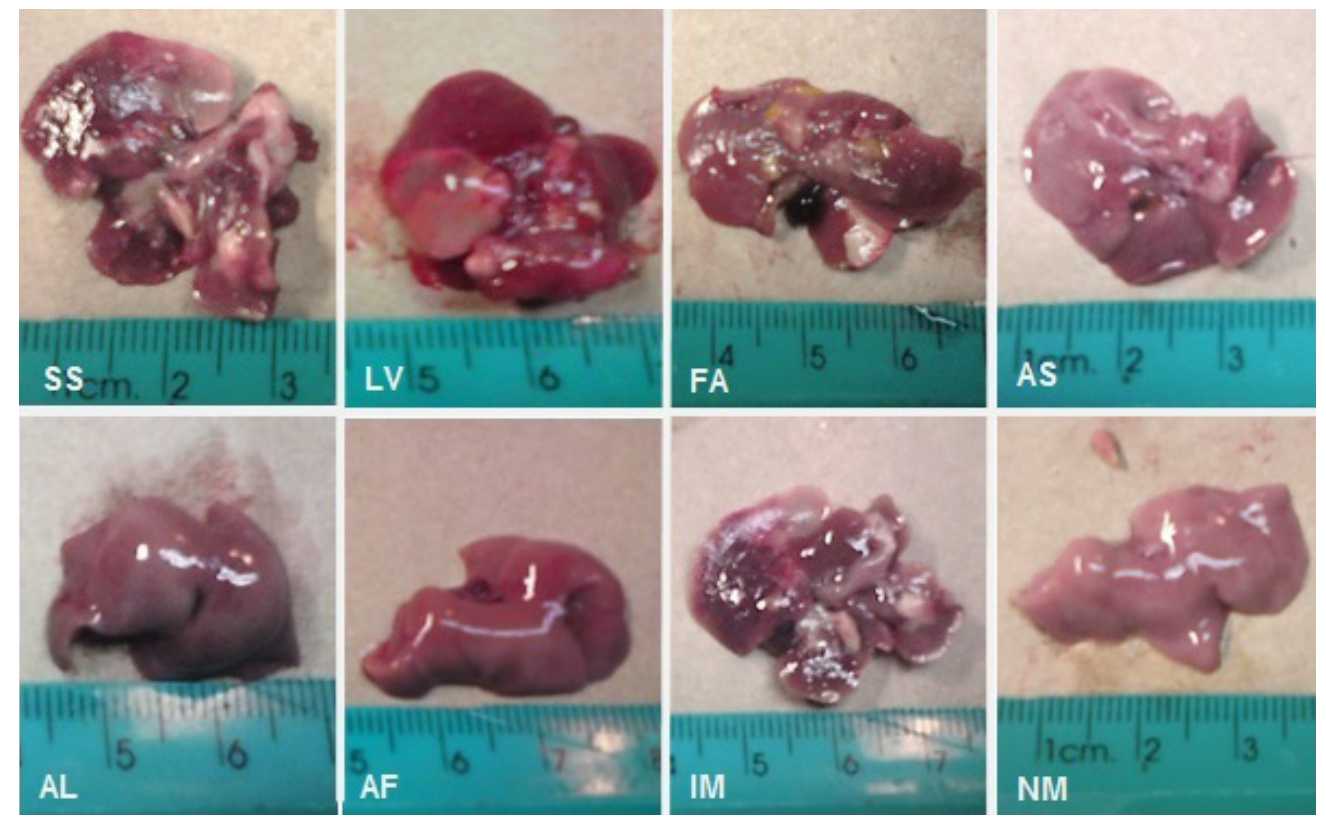

Fig. 3. Macroscopic lesions in livers of mice immunised with the excretory and secretory antigens of adults of Fasciola hepatica after a challenge infection. Livers were obtained five weeks post infection. A representative liver from each experimental group is shown, namely, mouse administered with a saline solution (SS), levamisole (LV) or Freund's Adjuvant (FA) and mouse immunised with the excretory and secretory antigens of adults of Fasciola hepatica in a saline solution (AS), levamisole (AL) or Freund's adjuvant (AF). In addition, the liver from non-infected (NM) and infected mice is shown (IM).

peared in the three groups with antigen (AS, AL and AF), but not in the control groups (LV, FA and SS). At week 6 postimmunisation, no antibodies were detected in the nonimmunised group, whereas in the groups with antigen administration, the antibodies reached their maximum level. Serum samples were pooled by group and analysed by Western blotting. A single band of $\sim 27 \mathrm{kDa}$ was recognised by all immunised groups (Fig. 2). Interestingly, serum samples of AL and AF groups were reactive since the second week postimmunisation, whereas sample of AS group was reactive until the fourth week postimmunisation. 


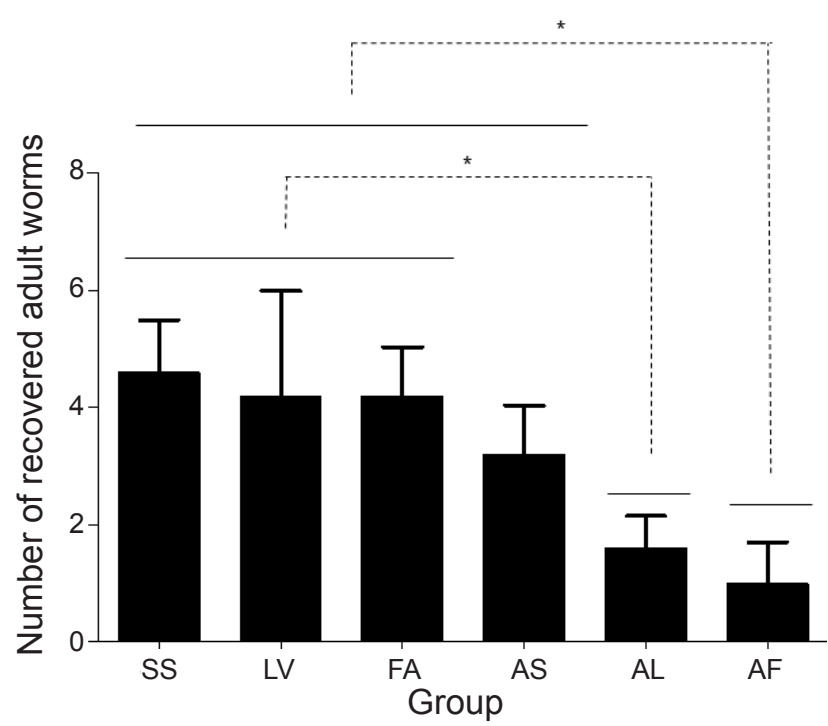

Fig. 4. Number of worms recovered from immunised mice with the excretory and secretory antigens of adults of Fasciola hepatica after the challenge infection. Parasites were obtained at five weeks post-infection. A representative liver from each experimental group is shown, namely mice immunised with the excretory and secretory antigens of adults of Fasciola hepatica in a saline solution (AS), levamisole (AL) or Freund's adjuvant (AF). Parasites recovered of mice administered only with a saline solution (SS), levamisole (LV) or Freund's Adjuvant (FA) are also shown. Statistical differences were determined by one-way ANOVA (*, P $<0.05)$

\section{Parasitic challenge}

In order to analyse protection induced after immunisation period (week 6 postimmunisation) mice were infected with 13 metacercariae. At five week's postinfection, livers of all mice were obtained, weighed and photographed before the counting parasites. Relationship between the liver and the body weight is showed in Table 1; livers of mice belonging to $\mathrm{AL}$ or $\mathrm{AF}$ groups were smaller than livers from the other groups. The length of livers was between $2.5 \mathrm{~cm}$ and $4.0 \mathrm{~cm}$ but no relationship was identified with the macroscopic lesions (Fig. 3) or the parasite load. The liver of healthy mice presented a normal colour without haemorrhagic areas or fibrotic parenchyma, compared with the livers of different treated groups that showed haemorrhagic and fibrotic areas in varying degrees. The livers of groups SS, LV and FA were often affected; haemorrhagic lesions cover most of the organs and in some of them the healing process reveals areas of fibrosis and blackened gall bladder due to haemorrhage and bile salts precipitation. In groups $\mathrm{AS}, \mathrm{AL}$ and $\mathrm{AF}$, the lesions did not affect the liver as a whole and areas with normal parenchyma were observed.

The parasite load was calculated after 5 weeks of the challenge infection with 13 metacercariae. Worms were recovered from liver parenchyma. No parasites were observed in the bile ducts. The number of recovered worms from the liver is shown in Fig. 4. Rates of worm recovering were classified in two categories, the first one was integrated by mice administered without antigen (SS, LV and FA); an average of 4 worms were recovered by each
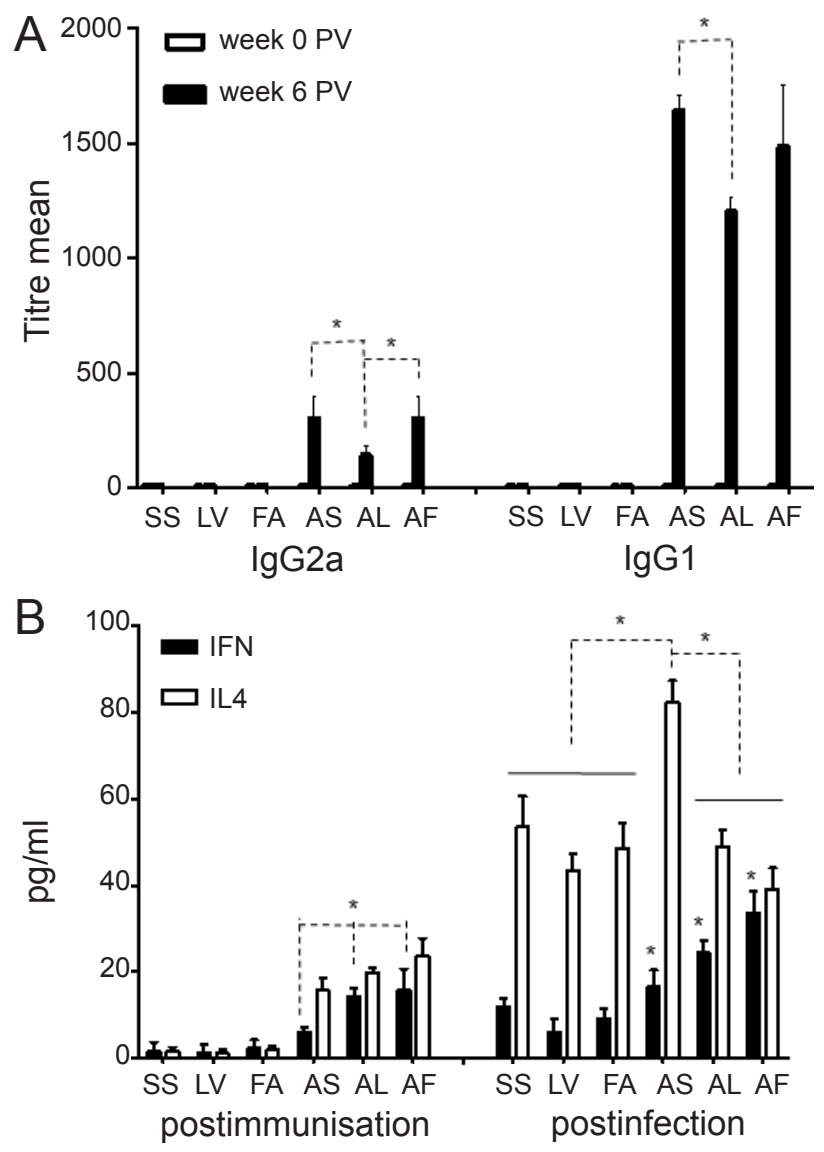

Fig. 5. Analysis of $\operatorname{IgG}$ isotypes and cytokines in serum samples of mice immunised with the excretory and secretory antigens of adults of Fasciola hepatica. Panel A shows the titre of IgG2a and $\mathrm{IgG1}$ isotypes to antigens of $F$. hepatica in serum samples of pre-immunised mice (week $0 \mathrm{PV}$ ) and hyperimmune serum samples (week 6 PV). Panel B shows the levels of cytokines IL-4 (open bars) and IFN- $\gamma$ (closed bars) after immunisation and after a challenge infection. Three groups of mice were immunised with the antigen in a saline solution (AS), in levamisole (AL) or in Freund's adjuvant (AF); the remaining groups were administered only with the saline solution (SS), levamisole (LV) or Freund's adjuvant (FA). Statistical differences were determined by twoway $\operatorname{ANOVA}(*, \mathrm{P}<0.05)$.

liver (percent of worm recovering, $35.4 \pm 0.2,32.3 \pm 0.4$ and $32.3 \pm 0.2$, respectively). In the second category, the average of recovered worms was of $3.2 \pm 0.8$ in AS group, $1.6 \pm 0.5$ in $\mathrm{AL}$ and $1 \pm 0.7$ in AF group. Parasite establishment ratio was of $24.6 \% \pm 0.3,12.3 \% \pm 0.3$ and $7.7 \% \pm 0.7$, respectively. The experimental groups were clustered in two categories, the first one was constituted by the groups administered without antigen (LV and FA) where a reduction of $8.7 \%$ was observed. In the immunised groups with antigen, reduction was of $30.4 \%$ in AS group, $65.2 \%$ in AL and $78.3 \%$ in AF. No relationship was observed between the parasite implantation and the postimmunisation or postinfection antibody level.

\section{Analyses of the immune response}

Fig. 5A shows the mean titres of IgG1 and IgG2a specific antibodies generated against the excretory and secretory antigens of adult worm of $F$. hepatica at six week postim- 
munisation. Levels of IgG1 in the groups of mice immunised with the antigens were significantly higher than those of IgG2a $(\mathrm{P}<0.05)$. Groups administered without antigen (SS, LV and FA) do not show specific antibody.

After immunisation, levels of IL-4 and IFN- $\gamma$ were only detected in AL and AF groups; although levels of cytokines were similar between groups, the IL-4 was ablated in AF group. After infection, levels of IL-4 were boosted in all groups. Levels of IFN- $\gamma$ boosted with some differences within the groups immunised with the antigen; the IFN- $\gamma$ increased two fold in AF and AS groups comparedd to AS group $(\mathrm{P}<0.05)$. In the groups of mice administered without antigen, the levels of IFN- $\gamma$ were detectable and similar between them (Fig. 5B).

\section{DISCUSSION}

In the present study, we compared the effects of levamisole and Freund's adjuvant on mice immunised with excretory and secretory antigens of adult worms of the liver fluke Fasciola hepatica. Since the indiscriminate administration of antiparasitic drugs could induce the selection of resistant parasites (Geerts and Gryseels 2000, Gilleard 2013, Van den Brom et al. 2013), it is necessary to investigate the immunogenic potential of parasitic proteins in addition to the study of substances that can be used as adjuvant.

In this work, production of IgG antibodies was analysed to determine if the usage of levamisole as adjuvant was able to stimulate the production of antibodies. Unexpected, antibody production occurs in all immunised groups with the parasite antigen, the levels of antibodies increase first in AF and AL groups with respect to AS group, but at the end of the immunisation schedule, antibody levels were similar in the groups administered with the antigens. These data confirm a high immunogenicity of the excretory and secretory adult worm antigens as previously reported by Walshe (2003), who immunised BALB/c mice polarised to Th2 immune response increasing the levels of IL-4 and the number of neutrophils, eosinophils and monocytes. Similar results were obtained by Younis et al. (2014) with the excretory and secretory antigens of Fasciola gigantica Cobbold, 1855.

Antibodies produced in mice of AF, AL and AS groups were able to recognise a $27 \mathrm{kDa}$ band in the antigens of Fasciola. This band has been previously reported as a group of enzymes known as cathepsin L cysteine proteinases (Collins et al. 2004, Dixit et al. 2008, Robinson et al. 2009, Younis et al. 2014). These proteins are important for juvenile worm migration (Cancela et al. 2008, Robinson et al. 2011) and are crucial for adult worm survival (Dalton et al. 2003, Stack et al. 2008).

One week after the end of the immunisation schedule, mice were challenged with 13 metacercariae and at fifth week postinfection liver lesions were analysed. The liver damage in the group administered without antigen was characterised by haemorrhagic, fibrotic and cirrhotic areas, similar to animals naturally infected (Rojo-Vázquez et al. 2012). In this group, 3 to 4 worms (between 23\% and $31 \%$ ) were recovered from each mouse; similar results were obtained with three experimentally infected naive mice (data not show). Data about worm recovering from liver were similar with previously reported ones (OlazabalManso et al. 1999), where $23 \%$ of worms were recovered from infected experimentally rats or mice. Although 0 to $7.5 \%$ of worm recovering from mice or rabbits experimentally infected has also been reported (Hussein and Khalifa 2008). The worms recovered in this study were alive, as they were moving; 5-7 mm long and $2 \mathrm{~mm}$ wide. According to the life cycle of $F$. hepatica and judging by the worm size and time of infection, recovered worms could be a juvenile stage. It is known that the adult worms develop in 2-3 months postinfection and are in the bile ducts. Regarding to the experimental groups, the lowest percentage of worm recovering was observed in $\mathrm{AL}$ and $\mathrm{AF}$ groups and the relationship between liver and body weight was significantly lower compared to the other groups. These data correlated with minimal macroscopic lesions observed in livers, where healthy parenchyma was found at the end of the experiment.

Chronic infection with $F$. hepatica stimulates Th2 immune responses while Th1 decreases (Walsh et al. 2009, Flynn et al. 2010); recent hypotheses propose that this condition ensures the parasite survival, as there are some suggesting data where Th2 immune response contributes to helminth survival. In contrast, Th1 response decreases the parasitic load. Administration of Quil A (a refined form of a saponin and a potent stimulant of Th1 response) during the course of experimental $F$. hepatica infection in 6-month-old sheep led to a significant reduction in faecal egg count and enhanced the levels of serum antibody activity (Haçariz et al. 2009). Immunisation of C57BL/6 mice with antigens obtained from the blood fluke Schistosoma japonicum mixed with levamisole induces a strong Th1 response that is effective to enhance the death of the parasite and prevent infection (Wang et al. 2008). The immunisation of Wistar rats with excretory antigens obtained from the nematode Trichinella spiralis in combination with the Freund's adjuvant enhances the IFN- $\gamma$ production, which is reflected in the decrease of the parasite load after a challenge infection (de la Rosa-Arana et al. 2012).

The results presented here are compatible with the fact that levamisole and the Freund's adjuvant are inductors of Th1 immune response (Billiau and Matthys 2001). After immunisation, levels of IFN- $\gamma$ increased in AL and AF groups compared to the others groups and, after infection, IFN- $\gamma$ boosted, whereas the levels of IL-4 remained similar in all groups except in AS group, where the IL-4 boosted two fold. Recently, it has been reported that thioredoxin peroxidase secreted by $F$. hepatica induces the alternative activation of macrophages (Donnelly et al. 2005).

The present data also suggest that antibodies were not able to induce a total protection against a challenge infection, since protection observed between immunised groups was different; in AS group, protection was of 30.4\%, whereas $65.2 \%$ and $78.3 \%$ in AL and AF groups, respectively. A recent hypothesis suggests that the immunity related to the activation of cells producing IFN- $\gamma$ is the mechanism that confers protection against Schistosoma mansoni Sambon, 1907 and $F$. hepatica during the experimental in- 
fection (Zhang et al. 2005, Cardoso et al. 2008, Wang et al. 2008, Miller et al. 2009). Our data support this hypothesis, since IFN- $\gamma$ levels increased in groups where the percentage of worm recovering decreased (AL and AF groups).

Currently, it is widely accepted that the infection by helminths enhances Th2 immune response, but according to the results of some studies where the protector activity of the immune response was analysed, Th2 response seems to be more regulatory than protective (MacDonald et al. 2002, Fabre et al. 2009, Gebreselassie et al. 2012, Peón et al. 2013). The present data also suggest that IFN- $\gamma$ production prevents the exacerbation of Th2 immune response and that is sufficient to decrease the parasite load. Since vaccine formulations require the use of safety adjuvant solutions, levamisole could be used as adjuvant. However, the Freund's adjuvant seems to be more appropriate for the preparation of vaccines. The collateral effects observed during the immunisation with the Freund's adjuvant sug- gest the importance of further studies to find safe adjuvant substances. The use of Freud's adjuvant is not recommended. Even for animal research, there are currently guidelines associated with its use, due to its painful reaction and potential tissue damage (Billiau and Matthys 2001).

In conclusion, our data suggest that the immunisation of mice with antigens of $F$. hepatica enhances the immune response avoiding liver damage and worm recovering after a challenge infection. Although the experimental model of fasciolosis is useful to elucidate the mechanism by which the parasite modulates immune responses, further studies are needed to characterise the juvenile worm antigens and the role of Th1 response in protection against $F$. hepatica.

Acknowledgements. We are grateful to María-Teresa Corona-Souza for technical attendance and to Irma Valle and Martín Piñon for taking care of the animals at the Institute for Epidemiological Diagnosis and Reference facilities. The English was reviewed by Romel Hernández-Bello.

\section{REFERENCES}

Bell R.G. 1996: IgE, allergies and helminth parasites: a new perspective on an old conundrum. Immunol. Cell Biol. 74: 337-345.

Billiau A., Matthys P. 2001: Modes of action of Freund's adjuvants in experimental models of autoimmune diseases. J. Leukoc. Biol. 70: 849-860.

Cadman E.T., Thysse K.A., Bearder S., Cheung A.Y.N, Johnston A.C., Lee J.J., Lawrence R.A. 2014: Eosinophils are important for protection, immunoregulation and pathology during infection with nematode microfilariae. PLoS Pathog. 10: e1003988.

Cancela M., Acosta D., Rinaldi G., Silva E., Durán R., RoChe L., Zaha A., Carmona C., Tort J.F. 2008: A distinctive repertoire of cathepsins is expressed by juvenile invasive Fasciola hepatica. Biochemie 90: 1461-1475.

Cardoso F.C., Macedo G.C., Gava E., Kitten G.T., Mati V.L., de Melo A.L., Caliari M.V., Almeida G.T., Venancio T.M., Verjovski-Almeida S., Oliveira S.C. 2008: Schistosoma mansoni tegument protein $\mathrm{Sm} 29$ is able to induce a Th1type of immune response and protection against parasite infection. PLoS Negl. Trop. Dis. 2: e308.

Collins P.R., Stack C.M., O’Neill S.M., Doyle S., Ryan T., Brennan G.P., Mousley A., Stewart M., Maule A.G., Dalton J.P., Donnelly S. 2004: Cathepsin L1, the major protease involved in liver fluke (Fasciola hepatica) virulence: propeptide cleavage sites and autoactivation of the zymogen secreted from gastrodermal cells. J. Biol. Chem. 279: 17038-17046.

Cuesta A., Esteban M.A., Meseguer J. 2002: Levamisole is a potent enhancer of gilthead seabream natural cytotoxic activity. Vet. Immunol. Immunopathol. 89: 169-174.

Dalton J.P., Neill S.O., Stack C., Collins P., Walshe A., Sekiya M., Doyle S., Mulcahy G., Hoyle D., Khaznadji E., Moiré N., Brennan G., Mousley A., Kreshchenko N., Maule A.G., Donnelly S.M. 2003: Fasciola hepatica cathepsin L-like proteases: biology, function, and potential in the development of first generation liver fluke vaccines. Int. J. Parasitol. 33: 1173-1181.

Dalton J.P., Robinson M.W., Mulcahy G., O’Neill S.M., Donnelly S. 2013: Immunomodulatory molecules of Fasciola hepatica: candidates for both vaccine and immunotherapeutic development. Vet. Parasitol. 195: 272-285.

Dawson-Saunders B., Trapp R.G. 2001: Bioestadística Médica (Second Edition). El Manual Moderno, Mexico City, 403 pp.
Dixit A.K., Dixit P., Sharma R.L. 2008: Immunodiagnostic/ protective role of cathepsin L cysteine proteinases secreted by Fasciola species. Vet. Parasitol. 154: 177-184.

Donnelly S., O’Neill S.M., Sekiya M., Mulcahy G., DalTON J. P. 2005: Thioredoxin peroxidase secreted by Fasciola hepatica induces the alternative activation of macrophages. Infect. Immun. 73: 166-173.

Fabre V., Beiting D.P., Bliss S.K., Gebreselassie N.G., Gagliardo L.F., Lee N.A., Lee J.J., Appleton J.A. 2009: Eosinophil deficiency compromises parasite survival in chronic nematode infection. J. Immunol. 182: 1577-1583.

Flynn R.J., Mulcahy G., Elsheikha H.M. 2010: Coordinating innate and adaptive immunity in Fasciola hepatica infection: implications for control. Vet. Parasitol. 169: 235-240.

Gebreselassie N.G., Moorhead A.R., Fabre V., Gagliardo L.F., Lee N.A., Lee J.J., Appleton J.A. 2012: Eosinophils preserve parasitic nematode larvae by regulating local immunity. J. Immunol. 188: 417-425.

Geerts S., Gryseels B. 2000: Drug resistance in human helminths: current situation and lessons from livestock. Clin. Microbiol. Rev. 13: 207-222.

Gilleard J.S. 2013: Haemonchus contortus as a paradigm and model to study anthelmintic drug resistance. Parasitology 140: 1506-1522.

GuY B. 2007: The perfect mix: recent progress in adjuvant research. Nat. Rev. Microbiol. 5: 505-517.

HaÇariz O., Sayers G., McCullough M., Garrett M., O’Donovan J., Mulcahy G. 2009: The effect of Quil A adjuvant on the course of experimental Fasciola hepatica infection in sheep. Vaccine 27: 45-50.

Hajnzić T.F., Kastelan M., Lukac J., Hajnzić T. 1999: Immunocompetent cells and lymphocyte reactivity to mitogens in levamisole-treated brain tumor children. Pediatr. Hematol. Oncol. 16: 335-340.

Hussein A.N., Khalifa R.M. 2008: Experimental infections with Fasciola in snails, mice and rabbits. Parasitol. Res. 102: 11651170.

Ibarra F., Montenegro N., Vera Y., Boulard C., Quiroz H., Flores J., OChOA P. 1998: Comparison of three ELISA tests for seroepidemiology of bovine fascioliosis. Vet. Parasitol. 77: 229-236.

Klion A.D., Nutman T.B. 2004: The role of eosinophils in host defense against helminth parasites. J. Allergy Clin. Immunol. 113: $30-37$. 
MacDonald A.S., Araujo M.I., Pearce E.J. 2002: Immunology of parasitic helminth infections. Infect. Immun. 70: 427-433.

McManus D.P., Dalton J.P. 2006: Vaccines against the zoonotic trematodes Schistosoma japonicum, Fasciola hepatica and Fasciola gigantica. Parasitology 133: S43-S61.

Miller C.M., Smith N.C., Ikin R.J., Boulter N.R, Dalton J.P., Donnelly S. 2009: Immunological interactions between 2 common pathogens, Th1-inducing protozoan Toxoplasma gondi and the Th2-inducing helminth Fasciola hepatica. PLoS ONE 4: e5692.

Mountford A.P., Pearlman E. 1998: Interleukin-12 and the host response to parasitic helminths; the paradoxical effect on protective immunity and immunopathology. Parasite Immunol. 20: 509-517.

Norma Oficial Mexicana NOM-062-ZOO-1999 2001: Especificaciones técnicas para la producción, cuidado y uso de los animales de laboratorio. Diario Oficial de la Federación, México.

O’Connell A.E., Hess J.A., Santiago G.A., Nolan T.J., LoK J.B., Lee J.J., AвRAнам D. 2011: Major basic protein from eosinophils and myeloperoxidase from neutrophils are required for protective immunity to Strongyloides stercoralis in mice. Infect. Immun. 79: 2770-2778.

Olazabal-Manso E., Morales-Monteagudo A., SerranoPérez H., Brito-Alberto E. 1999: Obtención de metacercarias de Fasciola hepatica en Lymnaea cubensis y relación parásito-hospedero en ratas Wistar y ratones BALB/c. Vet. Mex. 30: 109-115.

O’Neill S.M., Brady M.T., Callanan J.J., Mulcahy G., Joyce P., Mills K.H.G., Dalton J.P. 2000: Fasciola hepatica infection downregulates Th1 responses in mice. Parasite Immunol. 22: 147-155.

Peón A.N., Espinoza-Jiménez A., Terrazas L.I. 2013: Immunoregulation by Taenia crassiceps and its antigens. Biomed. Res. Int. 2013: 1-13.

Piedrafita D., Spithill T.W., Smith R.E., Raadsma H.W. 2010: Improving animal and human health through understanding liver fluke immunology. Parasite Immunol. 32: 572-581.

Robinson M.W., Corvo I., Jones P.M., George A.M., Padula M.P., To J., Cancela M., Rinaldi G., Tort J.F., Roche L., Dalton J.P. 2011: Collagenolytic activities of the major secreted cathepsin $\mathrm{L}$ peptidases involved in the virulence of the helminth pathogen, Fasciola hepatica. PLoS Negl. Trop. Dis. 5: e1012.

Robinson M.W., Menon R., Donnelly S.M., Dalton J.P., RANGANATHAN S. 2009: An integrated transcriptomics and proteomics analysis of the secretome of the helminth pathogen Fasciola hepatica: proteins associated with invasion and infection of the mammalian host. Mol. Cell. Proteomics 8: 1891-1907.

Rojo-Vázquez F.A., Meana A., Valcárcel F., MartínezVAlladares M. 2012: Update on trematode infections in sheep. Vet. Parasitol. 189: 15-38.

de la Rosa-Arana J.L., Campos-Rodríguez R., RiveraAguilar V., Escobar-Gutiérrez A., Miliar-García Á., Herrera-GonzÁlez N.E., Jarillo-Luna R.A. 2012: Com- parative effects of levamisole, Staphylococcus, and Freund's adjuvant on rat immunization with excretory and secretory antigens of Trichinella spiralis muscle larvae. Parasitol. Res. 111: 1599-1605.

Sajid M.S., Iqbal Z., Muhammad G., IQbal M.U. 2006: Immunomodulatory effect of various anti-parasitics: a review. Parasitology 132: 301-313.

Smooker P.M., Jayaraj R., Pike R.N., Spithill T.W. 2010: Cathepsin B proteases of flukes: the key to facilitating parasite control? Trends Parasitol. 26: 506-514.

Stack C.M., Caffrey C.R., Donnelly S.M., Seshaadri A., Lowther J., Tort J.F., Collins P.R., Robinson M.W., Xu W., McKerrow J.H., Craik C.S., Geiger S.R., Marion R., BRinen L.S., DALton J.P. 2008: Structural and functional relationships in the virulence-associated cathepsin L proteases of the parasitic liver fluke, Fasciola hepatica. J. Biol. Chem. 283: 9896-9908.

Tinoco-Velázquez I., Gómez-Priego A., Mendoza R., De la Rosa J.L. 2002: Searching for antibodies against Trichinella spiralis in the sera of patients with fever of unknown cause. Ann. Trop. Med. Parasitol. 96: 391-395.

Van-den-Brom R., Moll L., Borgsteede F.H., Van-Doorn D.C., Lievaart-Peterson K., Dercksen D.P., Vellema P. 2013: Multiple anthelmintic resistance of Haemonchus contortus, including a case of moxidectin resistance, in a Dutch sheep flock. Vet. Rec. 173: 552-553.

Venturiello S.M., Giambartolomei G.H., Costantino S.N. 1995: Immune cytotoxic activity of human eosinophils against Trichinella spiralis newborn larvae. Parasite Immunol. 17: 555559.

Walsh K.P., Brady M.T., Finlay C.M., Boon L., Mills K.H. 2009: Infection with a helminth parasite attenuates autoimmunity through TGF-beta-mediated suppression of Th17 and Th1 responses. J. Immunol. 183: 1577-1586.

Walshe A. 2003: Immune responses to Fasciola hepatica infection, and Fasciola hepatica derived antigens. Thesis. School of Biotechnology, Dublin City University, 163 pp.

Wang X., Jin H., Du X., Cai C., Yu Y., Zhao G., Su B., Huang S., Hu Y., Luo D., She R., Luo X., Zeng X., Yi X., Wang B. 2008: The protective efficacy against Schistosoma japonicum infection by immunization with DNA vaccine and levamisole as adjuvant in mice. Vaccine 26: 1832-1845.

Yin J., Jin H., Kang Y., XiaO C., Li X., Ding Z., Yang F., ZhU Q., WANG B. 2006: Efficacy of modified levamisole adjuvant on inactivated virus vaccine. Viral Immunol. 19: 525-535.

Younis M., Rabia I., El Deeb S., El Amir A. 2014: Fasciola gigantica excretory/secretory antigens as possible vaccine candidates. J. Med. Sci. 14: 1-11.

Zhang W.Y., Moreau E., Hope J.C., Howard C.J., Huang W.Y., Chauvin A. 2005: Fasciola hepatica and Fasciola gigantica: comparison of cellular response to experimental infection in sheep. Exp. Parasitol. 111: 154-159. antigens of adults of the liver fluke Fasciola hepatica Linnaeus, 1758. Folia Parasitol. 62: 047. 